\title{
Zeytin (Olea europaea) meyvesindeki bitki besin maddelerinin değişimi
}

\section{Changes of plant nutrients in olive (Olea europaea) fruit}

\author{
Tülin PEKCAN $^{1}$ iD Erol AYDOĞDU $^{1}$ iD, Hatice Sevim TURAN ${ }^{1}$ iD
}

${ }^{1}$ Zeytincilik Araştırma Enstitüsü Müdürlüğü, Bornova-İzmir

\section{To cite this article:}

Pekcan, T., Aydoğdu, E. \& Turan, H.S. (2020). Zeytin (Olea europaea) meyvesindeki bitki besin maddelerinin değişimi. Harran Tarım ve Gıda Bilimleri Dergisi, 24(4): 475483.

DOI:10.29050/harranziraat.795697

Address for Correspondence: Tülin PEKCAN

e-mail:

tulhan35@hotmail.com

Received Date:

16.09.2020

Accepted Date:

03.12.2020

(C) Copyright 2018 by Harran University Faculty of Agriculture. Available on-line at www.dergipark.gov.tr/harranziraat

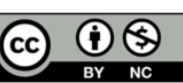

This work is licensed under a Creative Commons Attribution-Non Comm

\section{Öz}

Bu çalışma, fertigasyon sistemi ile gübreleme yapılan zeytin bahçelerinde, zeytin meyvesinin büyüme evrelerinde, bitki besin elementlerinin hangi zamanda ve miktarda uygulanmasını gerektiğini belirlemek amacı ile yapılmıştır.

$\mathrm{Bu}$ amaç doğrultusunda, verim çağındaki ayvalık zeytin çeşidi meyvelerinin (meyve eti + çekirdek) farklı gelişme dönemlerindeki $\mathrm{N}, \mathrm{P}, \mathrm{K}, \mathrm{Ca}, \mathrm{Mg}$ içeriklerinin değişimi ve $100 \mathrm{~kg}$ ürün ile kalkan $\mathrm{N}, \mathrm{P}_{2} \mathrm{O}_{5}, \mathrm{~K}_{2} \mathrm{O}, \mathrm{CaO}$ ve $\mathrm{MgO}$ miktarları belirlenmiştir. Çalışma İzmir Zeytincilik Araştırma Enstitüsü bahçesinde bulunan 32 yaşındaki Ayvalık zeytin çeşidinde yürütülmüştür. Tam çiçeklenmeden hasada kadar 6 dönemde (Haziran-Kasım) alınan meyve eti örneklerinde N (\% 0.55-1.58), P (\% 0.10-0.31), K (\% 1.24-1.77), Ca (\% 0.22-0.51), Mg (\% 0.05-0.09); çekirdek örneklerinde ise N (\% 0.45-180), P (\% 0.03-0.07), K (\% 0.11-0.29), Ca (\% 0.07-0.17), $\mathrm{Mg}$ (\% 0.02-0.05) değerleri arasında değiştiği belirlenmiştir. Bu çalışma ile zeytin meyvesinin gelişme periyodu süresince $\% \mathrm{~N}$ ve $\mathrm{K}^{\prime}$ nın çok değişken bir durum gösterdiği $P$, $\mathrm{Ca}$ ve $\mathrm{Mg}$ içeriklerinin ise daha istikrarlı olduğu gözlenmiştir. Zeytin ağacının $100 \mathrm{~kg}$ ürün ile $\mathrm{N} 350$ g, $\mathrm{P}_{2} \mathrm{O}_{5} 120$ g, K2O 660 g, CaO 2040 g ve MgO 40 g kaldırdığı belirlenmiştir.

Ürün ile en fazla $\mathrm{K}_{2} \mathrm{O}^{\prime}$ nun kaldırıldığı görülmektedir. Bu çalışma sonucunda fertigasyon programları hazırlanırken; toplam gübre miktarının sulama sayısına bölünmesinin yanında, meyvenin gelişme dönemlerine göre ihtiyaç duyduğu bitki besin elementlerinin doz ayarlaması yapılarak uygulanması sağlanacaktır. Bu şekilde hazırlanacak olan gübreleme programları ile çevre kirliliğine neden olmayan ve topraklarımızın korunmasını sağlayan bitkisel üretimin yapılmasına katkıda bulunulacaktır.

Anahtar Kelimeler: Bitki besleme, Gübreleme, Mevsimsel değişim, Zeytin meyvesi

\section{ABSTRACT}

This study was carried out in order to determine when and how much plant nutrients should be applied in the growing stages of olive fruit in olive orchards where fertilized with the fertigation system.

In line with this purpose, it was determined that the change of $\mathrm{N}, \mathrm{P}, \mathrm{K}, \mathrm{Ca}, \mathrm{Mg}$ contents in different growth stages of the fruits of Ayvalık olive variety in the yield age (fruit flesh+core) and the amounts of $\mathrm{N}, \mathrm{P}_{2} \mathrm{O}_{5}, \mathrm{~K}_{2} \mathrm{O}, \mathrm{CaO}$ and $\mathrm{MgO}$ were removed by $100 \mathrm{~kg}$ product. The study was carried out on 32 years old Ayvalık olive variety in the orchard of Izmir Olive Research Institute. In fruit flesh samples taken from full flowering until harvest in 6 periods (JuneNovember), it was determined that among the values of $\mathrm{N}(0.55-1.58 \%), \mathrm{P}(0.10-0.31 \%)$, $\mathrm{K}(1.24-1.77 \%), \mathrm{Ca}(0.22-0.51 \%), \mathrm{Mg}(0.05-0.09 \%)$ were changed; in the core samples, that among the values of $\mathrm{N}(0.45-180 \%), \mathrm{P}(0.03-0.07 \%), \mathrm{K}(0.11-0.29 \%), \mathrm{Ca}(0.07-0.17 \%), \mathrm{Mg}$ (0.02-0.05\%) were changed. With this study, it was observed that $\mathrm{N}$ and $\mathrm{K}$ showed a very variable situation and $\mathrm{P}, \mathrm{Ca}$ and $\mathrm{Mg}$ contents were more stable during the growing period of the olive fruit. It was determined that $350 \mathrm{~g} \mathrm{~N}, 120 \mathrm{~g} \mathrm{P}_{2} \mathrm{O}_{5}, 660 \mathrm{~g} \mathrm{~K}_{2} \mathrm{O}, 2040 \mathrm{~g} \mathrm{CaO}$ and 40 $\mathrm{g} \mathrm{MgO}$ were removed with the product by olive tree. It is seen that maximum $\mathrm{K}_{2} \mathrm{O}$ is removed by the product. In the result of this study, while preparing fertigation programs, in addition to dividing the total amount of fertilizer to the number of irrigation, it will be ensured that the plant nutrients needed by the fruit are applied by dose adjustment according to the growing period. With the fertilization programs to be prepared in this way, it will be contributed to the plant production that does not cause environmental pollution and ensures the protection of our soils.

Key Words: Plant nutrient, Fertilization, Seasonal change, Olive fruit 


\section{Giriş}

Ana vatanı Hatay, Kahramanmaraş, Mardin şeridi olan Zeytin (Olea europaea L), Doğu Akdeniz'in doğal bitki örtüsü olarak bilinmektedir (Mete ve Çetin, 2017). Tarih öncesi devirlerden bugüne kadar önemini koruyan ve bilinen en eski, en uzun süre ürün veren bir meyve ağacıdır. Türkiye ve diğer Akdeniz Havzası ülkeleri için ekonomik önem sahip olan zeytin, meyvesinin farklı şekillerde işlenerek sofralık ve yağı da sıvı yağ hammaddesi olarak değerlendirilmektedir. Insanların sağlıklı beslenmesinde olumlu etkilerinin bilimsel verilerle kanıtlanması sonucunda beslenmedeki önemi her geçen gün artmaktadır.

Dünyada dane zeytin üretimi FAO'nun 2018 verilerine göre 21 milyon ton olarak belirlenmiştir. Türkiye bu üretim içerisinde İspanya, İtalya, Fas'dan sonra 1.500 .467 ton ve \% 7.12'lik pay ile 4 . sırada (FAO, 2020) zeytinyağı üretimi dünyada 3.144.000 ton olarak bildirilirken; ülkemiz İspanya, İtalya Yunanistan Tunus'dan sonra 225.000 ton ve \% 7.16'lık pay ile 5. sırada yer almaktadır. Sofralık zeytin üretimi dünyada 2.925 .000 ton ülkemizde ise 414.000 ton ve $\% 14.5^{\prime}$ lik pay ile dünyada İspanya ve Mısırdan sonra 3. sırada yer almaktadır (IOC, 2020). Tüik verilerine göre Türkiye 154.037.215 adet meyve veren, 280.389.15 adet ürüne yatmamış olmak üzere toplam 182.076.130 adet ağaç varlığına sahiptir. Sofralık zeytin üretimi ağaç başına $9 \mathrm{~kg} /$ ağaç, yağıı zeytin üretimi 10 kg/ağaç şeklinde bildirilmektedir (TÜiK, 2019). Zeytin verimi periyodisite nedeniyle yıllar arasında farklılık göstermektedir. Dünyada sulanan alanlarda verim 50-65 kg/ağaç maksimum şartlarda ise $100 \mathrm{~kg} /$ ağaç olarak bildirilmektedir (FAO, 2019).

Türkiye'de 2018 yılında 426 bin ton sofralık, 1,1 milyon ton yağlık olmak üzere toplam 1,5 milyon ton zeytin üretimi yapılmıştır, yaklaşık 177 milyon zeytin ağacımız bulunmaktadır ve bu ağaçların \%15'i yeni tesis edilen bahçelerde olup, henüz verime ulaşmamıştır (Tüik, 2019). Ayrıca diğer ürünlerde olduğu gibi Türkiye'de de zeytin ağaçlarının da gübrelendiği ancak bu uygulamalarda bilimsel esaslara uyulmadığı, genelde tek taraflı ve çoğunlukla da yalnızca azotlu gübreleme yapıldığı görülmektedir. Dünya ortalamalarının altında olan zeytin verimini artırmak, kaliteyi düzeltmek ve periyodisiteden kaynaklanan üretim dalgalanmalarını azaltmak zeytin tarımının esas hedefidir (Doran ve Aydın, 1999; TÜik, 2011; Deliboran ve ark., 2019). Ancak son yıllarda yeni zeytin fidanlarının dikimi ve zeytin üretiminin özendirilmesi konusundaki çalışmaların da etkisiyle zeytin üretimi artış göstermiştir. Dünya ortalamaların altında olan zeytin verimini arttırmak, kaliteyi yükseltmek ve periyodisiteyi azaltmak, artan zeytin varlığına paralel olarak zeytin tarımında iyileştirilmesi gereken hedefler arasındadır. Diğer ürünlerde olduğu gibi zeytin ağaçlarının gübrelenmesinde toprak ve yaprak analizlerine dayalı bir gübreleme programı yapılmadığı genelde tek taraflı ve çoğunlukla da azotlu gübre uygulamalarının yapıldığı izlenmektedir. Sonuç olarak zeytin/zeytinyağı verim ve kalitesinin artırılması ülke çiftçisi ve ekonomisi açısından büyük önem arz etmektedir. Bu da ancak mevcut üretim alanlarının beslenme sorunlarının belirlenip ve elde edilecek sonuçlara göre yapılacak gübreleme çalışmaları ile mümkün olabilecektir.

Gübre uygulamalarını doğru bir şekilde yapabilmek için de zeytin ağacının ihtiyaç duyduğu besin elementlerinin içeriklerini bilmemiz gerekmektedir. Bu konu ile ilgili yapılan çalışmada 4 farklı yaş grubuna ait zeytin bahçelerinden seçilen 8'er adet ağaçta az ürün ve çok ürün yıllarında ağaçların yaş grupları dikkate alınmaksızın, ağacın farklı organlarından alınan örneklerdeki ortalama içerikleri (KM \%) sırasıyla N, $\mathrm{P}_{2} \mathrm{O} 5$ ve $\mathrm{K}_{2} \mathrm{O}$ dalda, $0.77,0.051,0.43$ yaprakta 1.53 , $0.12,0.66$ ve zeytin danesinde $1.18,0.20,2.84$ çekirdekte $0.69,0.061,0.10$ şeklinde bildirilmiştir. Yaprak ve çekirdeğin bünyesinde \% olarak azot en fazla bulunurken dane etinde en fazla potasyumun bulunduğu görülmektedir (Dikmelik 1984; Pekcan ve ark., 2004). Aynı çalışmada $1 \mathrm{~kg}$ odun + yaprak ile kaldırılan $\mathrm{N}, \mathrm{P}_{2} \mathrm{O}_{5}$ ve $\mathrm{K}_{2} \mathrm{O}$ miktarları $7.04 \mathrm{~g}, 0.90$ $\mathrm{g}$ ve $3.10 \mathrm{~g}$ olarak ifade edilmiştir. \% besin maddesi miktarları ile ağaçların ürün miktarı durumuna 
göre, ağaç başına alınan ürün miktarı ne olursa olsun ürün ile (meyve eti + çekirdek) en çok potasyum daha sonra azot, budama artıkları ile topraktan en çok azot ve daha sonra potasyumun kaldırıldığı belirlenmiştir. Farklı bir çalışmada Domat, Memecik, ve Gemlik çeşitlerin kaldırdığı besin maddeleri, ağaç başına aynı miktarda ürün alma koşulu ile diğer çeşitlere göre Domat zeytin çeşidine \% $20 \mathrm{~N}, \% 50 \mathrm{P}$ ve \% $30 \mathrm{~K}$ 'nın daha fazla miktarda verilmesi gerektiğini belirlemiştir (Sarıfakıoğlu, 1995). Gemlik zeytin çeşidinde yapılan bir çalışmada, azot ve potasyum zeytinlerde etkileri en belirgin olan elementlerdir. Zeytin ağaçları ihtiyaç duydukları azotun iki katı potasyuma gereksinim duyduklarını belirtmektedir (Haspolat, 2009). Yapılan çalışmalar ürün ile kalkan bitki besin maddelerinin miktarlarının toplam içerisinde büyük bir paya sahip olduğunu göstermektedir. Bu nedenle özellikle fertigasyon programlarının doğru bir şekilde yapılabilmesi için zeytin meyvesinin oluşumundan hasada kadar geçen zamanda ihtiyaç duyulan besin elementlerinin miktarlarını dönemlere göre bilmemiz gerekmektedir. Fakat zeytin meyvesi ile ilgili sınır değerlerinin bulunmaması nedeni ile meyvedeki besin maddelerinin yeterlilik durumları ile ilgili adına uygun karar verilememektir. Domat zeytin çeşidinde meyve yaprak besin elementleri değişimlerinin incelendiği çalışmada zeytin meyvesinde bitki besleme ile ilgili referans aralığının olmaması sebebiyle, sonraki çalışmalara ışık tutması açısından; üst üste üç yıl meyve ve beraberinde yaprak örnekleri de alınarak bitki besin maddelerinin değişimleri ve miktarları verilmiştir (Zincircioğlu, 2018).

Amacına uygun fertigasyon programları hazırlayabilmek için yaygın olarak yetiştiriciliği yapılan Kuzey Ege bölgesine iyi adapte olmuş, Ayvalık zeytin çeşidi kullanılmıştır. Genellikle yağlık olarak kullanılırken pembe olum döneminde "çizme zeytin" siyah olum döneminde de "sele tipi siyah" zeytin olarak değerlendirilebilmektedir. Her zeytin çeşidinin ihtiyaç duyduğu bitki besin maddesi içeriği çeşide göre farklılık göstermektedir.

Ayvalık zeytin çeşidi meyvelerinin büyüme evreleri boyunca meyvedeki bitki besin element içerikleri belirlenerek fertigasyon sisteminden uygulanacak $N, P$ ve $K$ içeren gübrelerin uygulama zamanlarına yol gösterici olacaktır. Bunun yanında meyve ile kaldırılan $\mathrm{N}, \mathrm{P}_{2} \mathrm{O}_{5}, \mathrm{~K}_{2} \mathrm{O}$ miktarları belirlenerek uygulanacak olan gübre miktarlarının belirlenmesine katkı sağlayacaktır.

\section{Materyal ve Metot}

Çalışma Bornova Zeytincilik Araştırma Enstitüsü deneme arazisinde bulunan, 32 yaşındaki Ayvalık zeytin çeşidinde yapılmıştır. Deneme alanında iki farklı derinlikten (0-30 ve $30-60 \mathrm{~cm}$ ) alınan toprak örnekleri hava kurusu hale getirildikten sonra öğütülerek 2 mm'lik elekten geçirilerek analize hazır hale getirilmiştir. Bu örneklerde $\mathrm{pH}$ (1:2.5 toprak:su), EC (dS $\mathrm{m}^{-1}$ ), Kireç (Scheibler Kalsimetresi, \%), Organik Madde (Walkley-Black Metodu, \%) ve Bünye (Hidrometre Metodu), N (Kjeldahl Metot, \%), P (Olsen Metot, $\mathrm{mg} \mathrm{kg}^{-1}$ ), K $\left(\mathrm{mg} \mathrm{kg}^{-1}\right)$, Ca $\left(\mathrm{mg} \mathrm{kg}^{-1}\right)$ and $\mathrm{Mg}\left(\mathrm{mg} \mathrm{kg}^{-1}\right)$, ICP-OES cihazı ile belirlendi. Çalışmaya başlamadan önce deneme alanı toprağının bazı fiziksel ve kimyasal özellikleri Çizelge 1 'de verilmiştir.

Hasat sonrasında bahçeyi temsil edecek şekilde Doğu, Güney, Batı ve Kuzey yönleri olmak üzere ağaçların 4 farklı yönünden, ağaç tacının orta kısmına gelen bir yıllık dallardan karşılıklı yaprak çiftinin alınması şeklinde toplamda 100 adet yaprak örnekleri alınmıştır (Doran ve Aydın, 1999). Laboratuvara getirilen yaprak örnekleri önce çeşme suyu, sonra sırasıyla 2 defa deiyonize su ile yıkanarak kurutma dolabında $65^{\circ} \mathrm{C}$ de 48 saat (sabit ağırlığa gelinceye kadar) kurutulup, değirmende öğütülerek analize hazır duruma getirilmiştir. Çalışmaya başlamadan önce deneme ağaçlarına ait yaprak örneklerinin analiz sonuçları Çizelge 2'de verilmiştir. 
Çizelge 1. Deneme alanı toprağının bazı fiziksel ve kimyasal özellikleri

Table 1. Some physical and chemical properties of experimental soil

\begin{tabular}{|c|c|c|c|c|}
\hline \multicolumn{3}{|l|}{$\begin{array}{l}\text { Toprak analizleri } \\
\text { (Soil analysis) }\end{array}$} & \multicolumn{2}{|c|}{$\begin{array}{l}\text { Toprak derinliği } \\
(\mathrm{cm}) \\
\quad \text { (Soil depth } \mathrm{cm})\end{array}$} \\
\hline & & & $0-30$ & $30-60$ \\
\hline $\mathrm{pH}$ & & & 7.64 & 7.78 \\
\hline EC & \multirow{2}{*}{\multicolumn{2}{|c|}{$\mathrm{dS} \mathrm{m}^{-1}$}} & 0.50 & 0.36 \\
\hline $\begin{array}{l}\text { Bünye } \\
\text { (Structure) }\end{array}$ & & & \multicolumn{2}{|c|}{$\begin{array}{c}\text { Kumlu Tın } \\
\text { (sandy loam) }\end{array}$} \\
\hline $\begin{array}{l}\text { Kum } \\
\text { (Sand) }\end{array}$ & \multirow{6}{*}{\multicolumn{2}{|c|}{$\%(<w / w)$}} & 72 & 73 \\
\hline $\begin{array}{l}\text { Silt } \\
\text { (Silt) }\end{array}$ & & & 12 & 12 \\
\hline $\begin{array}{l}\text { TIn } \\
\text { (Loamy) }\end{array}$ & & & 16 & 15 \\
\hline $\begin{array}{l}\text { Kireç } \\
\text { (Lime) }\end{array}$ & & & 2.89 & 3.01 \\
\hline $\begin{array}{l}\text { Organik Madde } \\
\text { (Organic matter) }\end{array}$ & & & 1.38 & 1.02 \\
\hline $\begin{array}{l}\text { Toplam N } \\
\text { (Total nitrogen) }\end{array}$ & & & 0.12 & 0.10 \\
\hline \multirow{9}{*}{$\begin{array}{l}\text { Alınabilir } \\
\text { (Available) }\end{array}$} & $P$ & \multirow{9}{*}{$\mathrm{mg} \mathrm{kg}^{-1}$} & 28.97 & 25.74 \\
\hline & $\mathrm{K}$ & & 288.35 & 302.37 \\
\hline & $\mathrm{Ca}$ & & 3591 & 3678 \\
\hline & $\mathrm{Mg}$ & & 103 & 107 \\
\hline & $B$ & & 1.85 & 1.87 \\
\hline & $\mathrm{Cu}$ & & 4.01 & 2.84 \\
\hline & $\mathrm{Fe}$ & & 2.95 & 2.41 \\
\hline & $\mathrm{Mn}$ & & 5.45 & 6.34 \\
\hline & $\mathrm{Zn}$ & & 4.13 & 6.67 \\
\hline
\end{tabular}

Tam çiçeklenmeden 2 hafta sonra başlayarak hasada kadar 6 dönemde (meyve tutumu, çekirdek oluşumu, çekirdek sertleşmesi, yeşil olum, pembe olum, siyah olum) 48 adet ağaçtan alınan meyve örnekleri (meyve eti ve çekirdek) gerekli işlemlerden geçirilerek $65^{\circ} \mathrm{C}$ 'de kurutulup, öğütüldükten sonra analize hazırlanmıştır (Kacar, 1972). Yaprak ve meyve örneklerinde N (Makro Kjeldahl Metodu) Kacar ve Inal, (2008), Toplam $P$, $\mathrm{K}, \mathrm{Ca}, \mathrm{Mg}, \mathrm{Na}, \mathrm{B}, \mathrm{Cu}, \mathrm{Fe}, \mathrm{Mn}$ ve $\mathrm{Zn}\left(\mathrm{H}_{2} \mathrm{O}_{2}+\mathrm{HNO}_{3}\right)$ asit ile mikrodalga yakma cihazında yakılıp elde edilen süzüklerde ICP-OES cihazı ile belirlenmiştir (Zarcinas, 1987).

Çizelge 2. Deneme ağaçlarına ait yaprak örneğinin analiz sonuçları

Table 2. Analysis results of the leaf sample of the experimental trees

\begin{tabular}{|c|c|c|c|c|c|c|c|c|c|}
\hline \multicolumn{1}{|c|}{ Yaprak örneği analiz sonuçları } \\
(Analysis results of the leaf sample) \\
\hline $\mathrm{N}$ & $\mathrm{P}$ & $\mathrm{K}$ & $\mathrm{Ca}$ & $\mathrm{Mg}$ & $\mathrm{B}$ & $\mathrm{Cu}$ & $\mathrm{Fe}$ & $\mathrm{Mn}$ & $\mathrm{Zn}$ \\
\hline \multicolumn{6}{|c|}{$\%(\mathrm{w} / \mathrm{w})$} & \multicolumn{7}{c|}{$\mathrm{mg} \mathrm{kg}^{-1}$} \\
\hline 1.41 & 0.12 & 0.73 & 2.11 & 0.11 & 16.95 & 45.28 & 168.31 & 32.89 & 15.24 \\
\hline
\end{tabular}

Verilerin değerlendirilmesinde JMP 7.0 istatistik programı kullanılmıştır.

\section{Araştırma Bulguları ve Tartışma}

Ayvalık zeytin çeşidinde meyve tutumundan itibaren hasada kadar olan dönemde alınan meyve eti ve çekirdek örneklerinin kuru maddede ki (KM) $\mathrm{N}$ içerikleri incelendiğinde $\mathrm{N}$ içeriği 2. dönemde keskin bir azalma gösterirken meyve etinde daha sonra 5 . döneme kadar artarak devam etmektedir (Şekil 1).
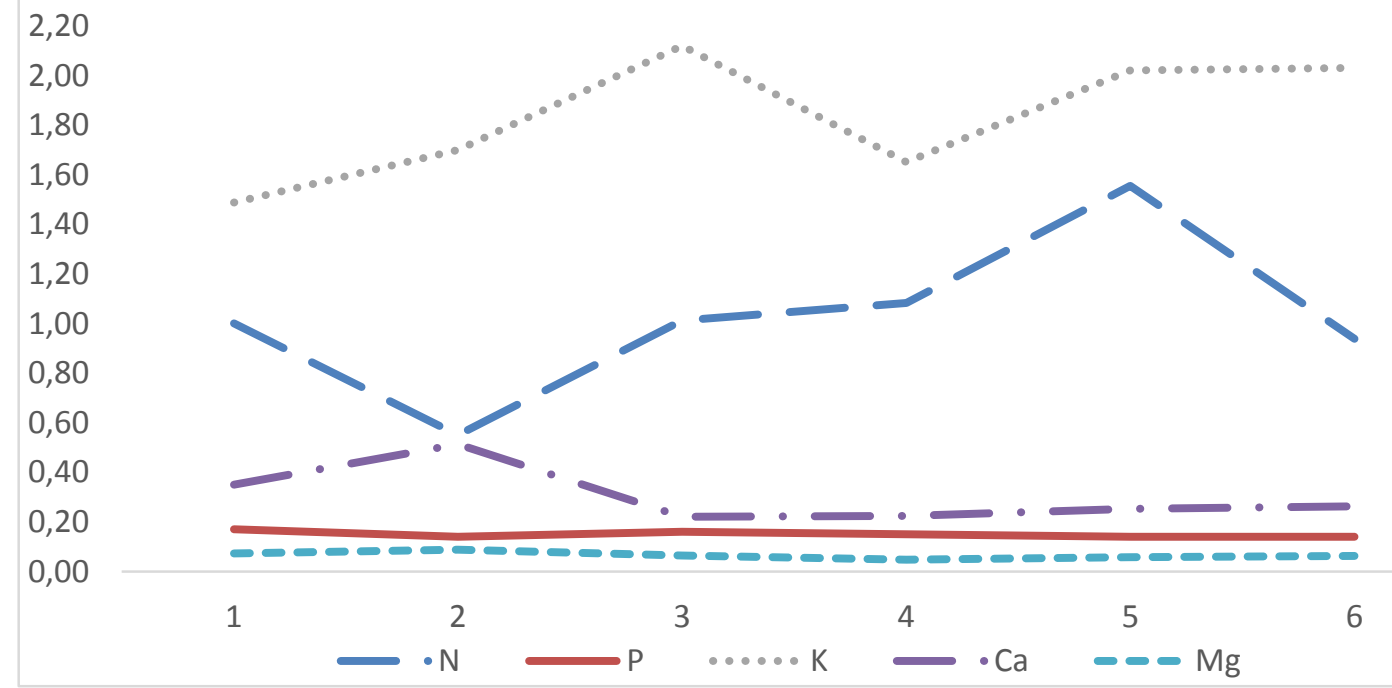

Şekil 1: Meyve etinde kuru maddede \% N, P, K, Ca ve Mg içeriklerinin gelişme dönemlerine göre değişimi

Figure 1. The variation of $N, P, K, C a$ and $M g$ contents dry matter (\%) of fruit flesh according to the growing periods 
$\mathrm{Bu}$ dönemden sonra ani bir azalma söz konusudur. $\mathrm{Bu}$ da $\mathrm{N}$ elementinin meyveden yaprağa doğru geri taşınım yaptığını göstermektedir. Diğer makro ve mikro bitki besin element içerikleri incelendiğinde $\mathrm{P}, \mathrm{Ca}, \mathrm{Mg}$ ve
Cu'da büyüme evreleri boyunca stabil bir durum göstermektedir. Bunun yanında 3. dönemde $\mathrm{K}, \mathrm{Fe}$ ve $Z n^{\prime}$ da ani bir artış göstermektedir. (Çizelge 3 ve 4).

Çizelge 3. Meyve etinin makro ve mikro bitki besin element içerikleri

Table 3. Macro and micro nutrient element contents of fruit flesh

\begin{tabular}{|c|c|c|c|c|c|c|c|c|c|c|}
\hline \multirow{3}{*}{$\begin{array}{l}\text { Dönem } \\
\text { (Period) }\end{array}$} & \multicolumn{10}{|c|}{$\begin{array}{l}\text { Meyve eti } \\
\text { (Fruit flesh) }\end{array}$} \\
\hline & $\mathrm{N}$ & $\mathrm{P}$ & $\mathrm{K}$ & $\mathrm{Ca}$ & $\mathrm{Mg}$ & B & $\mathrm{Cu}$ & $\mathrm{Fe}$ & $\mathrm{Mn}$ & $\mathrm{Zn}$ \\
\hline & \multicolumn{5}{|c|}{$\%$} & \multicolumn{5}{|c|}{$\mathrm{mg} \mathrm{kg}^{-1}$} \\
\hline 1. & 1.00 & 0.17 & 1.24 & 0.35 & 0.07 & 20.13 & 7.71 & 26.97 & 10.74 & 22.14 \\
\hline 2. & 0.55 & 0.12 & 1.42 & 0.51 & 0.09 & 21.06 & 6.76 & 33.17 & 16.68 & 13.95 \\
\hline 3. & 1.58 & 0.10 & 1.77 & 0.22 & 0.07 & 10.41 & 8.61 & 47.10 & 7.40 & 20.44 \\
\hline 4. & 1.50 & 0.31 & 1.38 & 0.23 & 0.05 & 25.30 & 8.77 & 19.51 & 5.87 & 13.65 \\
\hline 5. & 1.23 & 0.10 & 1.68 & 0.25 & 0.06 & 15.66 & 7.19 & 13.46 & 6.17 & 12.55 \\
\hline 6. & 0.73 & 0.10 & 1.69 & 0.26 & 0.06 & 25.43 & 7.25 & 28.18 & 6.15 & 12.81 \\
\hline
\end{tabular}

Çizelge 4. Çekirdek makro ve mikro bitki besin element içerikleri

Table 4. Macro and micro nutrient contents of stone

\begin{tabular}{|c|c|c|c|c|c|c|c|c|c|c|}
\hline \multirow{3}{*}{$\begin{array}{l}\text { Dönem } \\
\text { (Period) }\end{array}$} & \multicolumn{10}{|c|}{$\begin{array}{c}\text { Çekirdek } \\
\text { (Stone) }\end{array}$} \\
\hline & $\mathrm{N}$ & $P$ & K & $\mathrm{Ca}$ & $\mathrm{Mg}$ & $B$ & $\mathrm{Cu}$ & $\mathrm{Fe}$ & $\mathrm{Mn}$ & $\mathrm{Zn}$ \\
\hline & \multicolumn{5}{|c|}{$\%$} & \multicolumn{5}{|c|}{$\mathrm{mg} \mathrm{kg}^{-1}$} \\
\hline 3. & 1.80 & 0.03 & 0.11 & 0.09 & 0.02 & 4.93 & 2.70 & 6.77 & 3.09 & 5.52 \\
\hline 4. & 1.45 & 0.07 & 0.29 & 0.17 & 0.05 & 4.52 & 2.38 & 6.13 & 2.59 & 4.85 \\
\hline 5. & 0.48 & 0.04 & 0.24 & 0.09 & 0.03 & 13.24 & 5.07 & 7.41 & 5.69 & 8.37 \\
\hline 6. & 0.45 & 0.03 & 0.21 & 0.07 & 0.02 & 13.24 & 5.00 & 7.31 & 5.49 & 8.27 \\
\hline
\end{tabular}

Sarıfakıoğlu (1995) farklı zeytin çeşitlerinde iki yıl üst üste yaptığı çalışmada hasat döneminde yaş ağırlıkta meyve etinde $\mathrm{N} \%$ 0.44-045, P \% 0.0470.06 çekirdekte \% N 0.444-0.453, \% P 0.038-0.043 olarak belirlemiştir. Dikmelik (1984) aynı çeşitte yaptığı çalışmada kuru madde de meyve etinde \% N 1.178, \% P 2.84 çekirdekte ise \% N 0.685, \% P 0.061 olarak belirlemiştir. Yine Seferoğlu (1996) Ayvalık çeşidinde yaptığı çalışmada \% N 0.3750.746, \% P 0.025-0.144, Jordao ve Leitao (1990) farklı bir çeşitte \% N 0.54-2.07, \% P 0.08-0.30 olarak belirlemişlerdir. Potasyum içeriği kuru maddede, meyve etinde oluşumundan itibaren 3. örnek alma dönemine kadar artarak devam ediyor, 3.-4. dönem arasında azalma meydana gelirken daha sonra tekrar hasada kadar artarak devam ediyor. Çekirdekte ise önce artış sonra azalma şeklindedir. Zincircioğlu (2010), \% K 0.55-0.75, Sarıfakıoğlu (1995), \% K 0.29-1.02, yaş ağırlık olarak belirlerken Seferoğlu (1996), kuru madde de \% K
1.26-186, Jordao ve Leitao (1990) \% K 0.98-3.56, Dikmelik (1984), 2.17-3.93, Papastamataki (1971) \% K 0.66 ve Ferreira (1984) \% K 2.68 olarak belirlemişlerdir.

Kalsiyum elementinde meyve eti ve çekirdekte 2. dönemde biraz artış daha sonra 3. dönemden hasada kadar stabil devam etmektedir. Kuru madde de Seferoğlu (1996), \% Ca 0.048-0.069 Eryüce ve Püskülcü (1995) ayvalık zeytin çeşidinde \% 0.063 belirlerken elde ettikleri değerler çalışmamızdaki değerlerden daha düşük düzeydedir.

Magnezyum meyve etinde ve çekirdekte Haziran-Temmuz aylarında artış daha sonra azalma ile hasada gelmektedir. Seferoğlu (1996), Jordao ve Leitao (1990) kuru maddede yaptıkları çalışmada \% $\mathrm{Mg}$ içerikleri ile çalışmamızla benzer sonuçlar elde etmişlerdir. 
Çizelge 5. Hasat döneminde meyve eti ve çekirdekteki \% N, $\mathrm{P}_{2} \mathrm{O}_{5}, \mathrm{~K}_{2} \mathrm{O}, \mathrm{CaO}$ ve $\mathrm{MgO}$

Table 5. The contents of $\mathrm{N}, \mathrm{K}_{2} \mathrm{O}, \mathrm{CaO}$ and $\mathrm{Mg}(\%)$ of fruit flesh and pit in the harvest period

\begin{tabular}{|l|c|c|}
\hline \multirow{2}{*}{$\begin{array}{l}\text { Bitki besin elementi (\%) } \\
\text { (Plant nutrient) }\end{array}$} & \multicolumn{2}{|c|}{$\begin{array}{c}\text { Hasat dönemi } \\
\text { (Harvest period) }\end{array}$} \\
\cline { 2 - 3 } & Meyve eti & Çekirdek \\
\hline $\mathrm{N}$ & 0.94 & 0.45 \\
\hline $\mathrm{P}_{2} \mathrm{O}_{5}$ & 0.32 & 0.07 \\
\hline $\mathrm{K}_{2} \mathrm{O}$ & 2.42 & 0.25 \\
\hline $\mathrm{CaO}$ & 0.37 & 0.10 \\
\hline $\mathrm{MgO}$ & 0.10 & 0.03 \\
\hline
\end{tabular}

Meyve etinde mikro elementler çok değişken bir durum göstermektedir. Çekirdekte ise meyvenin büyümesi ile mikro besin elementi içerikleri stabil kalmaktadır. Çalışmamızda elde edilen sonuçlar KM'de yapılan çalışmalarla benzerlik göstermektedir. Seferoğlu (1996) ayvalık çeşidinde yaptığı çalışmada KM'de B 11.50-48 ppm, Cu 3.43-15.92 ppm, Fe 1.76-31.86 ppm, Mn 1.72-14.35 ppm, Zn 5.15-15.93 ppm bulmuştur. Eryüce ve Püskülcü, (1995) yine aynı aynı çeşitte yaptıkları çalışmada B 18-21 ppm, Cu 5.50-6.98 ppm, Mn 1.48-2.54 ppm, Zn 4.65-7.39 olarak belirtmektedir. Zincircioğlu (2018), taze meyve örnekleri 3 yıllık yaptığı çalışmada ortalama \% N 0.5, \% P 15.97, \% K 1.78, \% Ca 0.09 ve \% Mg 0.03 olarak belirlemiştir.

Hasat döneminde alınan meyve örneklerine ait kuru maddedeki bitki besin element içerikleri incelendiğinde meyve eti ile en fazla \% $2.42 \mathrm{~K}_{2} \mathrm{O}$ bunu \% 0.94 ile $\mathrm{N}$ izlemektedir (Çizelge 5). Çekirdeğin içerdiği besin maddeleri incelendiğinde \% $0.45 \mathrm{~N}$ ve ikinci sırada \% $0.25 \mathrm{~K}_{2} \mathrm{O}^{\prime}$ un yer aldığı görülmektedir.

Üçüncü dönemden itibaren sertleşen çekirdekte kuru maddede bulunan \% N, P, K, Ca ve Mg değişimleri Şekil 2'de incelendiğinde besin elementlerinde çekirdekten meyve etine doğru taşınımın olduğu, N'da bu azalmanın çok keskin olduğu, P aynı meyve etinde olduğu gibi stabil seyrettiği gözlenmektedir. Potasyum, meyve gelişiminin 3-4. döneminde meyve etindeki miktar azalırken çekirdekte artış olarak kendini göstermektedir. Daha sonraki dönemlerde değişim göstermemektedir. Kalsiyum 3-4. dönemde çok az bir artı̧̧ gösterdikten sonra meyve etiyle uyumlu olarak stabil bir durum sergilemektedir.

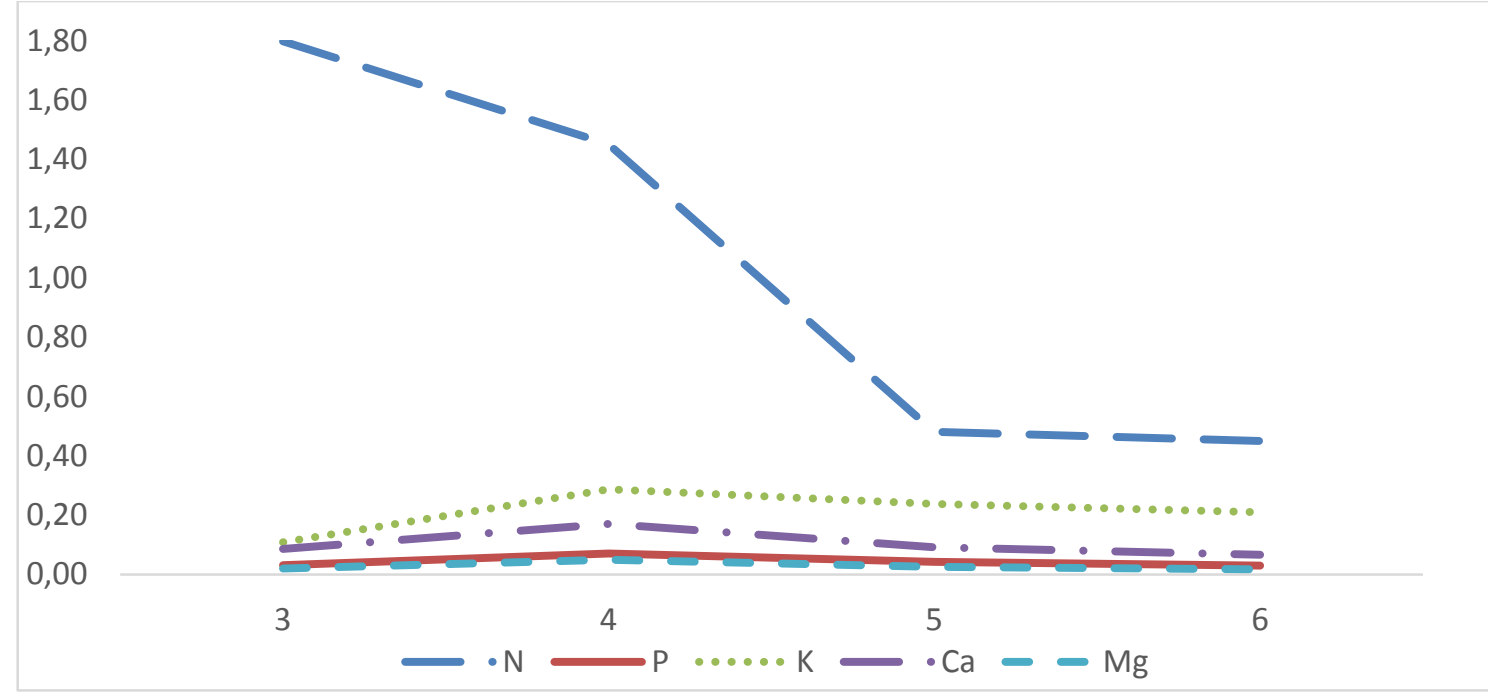

Şekil 2. Çekirdekte \% N, P, K, Ca ve Mg içeriklerinin gelişme dönemlerine göre değişimi Figure 2. The variation of $N, P, K, C a$ and $M g$ contents (\%) of pit according to the growing periods

Çizelge 5 incelendiğinde meyve örneklerinde \% $N$ içeriğinin en düşük olduğu dönem çekirdek oluşumu ve yeşil olum dönemleri, en yüksek olduğu dönem ise pembe olum dönemi olarak görülmektedir. \% P içeriği genellikle stabil bir seyir göstermekle birlikte en düşük çekirdek oluşumu dönemindedir. Pembe olum dönemi dışında istatistiki açıdan aynı grup içerisinde yer almaktadır. \% $\mathrm{K}$ içeriğinin en düşük olarak meyve tutum dönemi, en yüksek ise çekirdek sertleşmesi olarak belirlenmiştir. \% Ca içeriği çekirdek sertleşmesi ve yeşil olum dönemlerinde en düşük seviyede ve istatistiki olarak aynı grup içerisinde yer almaktadır. \% Mg içeriği en düşük yeşil olum 
döneminde, en yüksek meyve tutumunda belirlenmiş ve istatistiki olarak da ayrı grupta yer almıştır. Haspolat (2009), Gemlik zeytin çeşidinde malçlı ve malçsız ortamlarda yaprak gübresinin farklı dozlarının uygulanması ile yaptığı çalışmada meyve örneklerinde ortalama \% N 0.31, \% K 0.971.02, \% Mg 0.1 ve \% $\mathrm{Zn}$ 11.1-15 şeklinde belirlemiştir. Özilbey (1997), bitki büyüme düzenleyicileri ve yaprak gübreleri ile 1994-1995 yıllarında yaptığı çalışmada meyve örneklerinin yıllara ve örnek alma dönemlerine göre değişkenlik gösterdiğini belirtmiştir. Yaş ağırlık üzerinden meyve etinde \% N içeriklerinin 0.22-0.75 \% K içeriğinin 0.2-2.5 arasında, \% Mg içeriğinin 0.051.24 ve $\% \mathrm{Zn}$ içeriğinin de $2-52 \mathrm{mg} \mathrm{kg}^{-1}$ arasında değiştiğini belirlemiştir.

Mikro besin elementlerinden B içeriği en düşük çekirdek sertleşmesi döneminde belirlenirken en yüksek ise siyah olum döneminde görülmüştür. Bakır içeriği en düşük çekirdek oluşumunda en yüksek pembe olum döneminde belirlenmiştir.
Demir içeriği meyve tutumundan pembe olum dönemine kadar hem çok değişkenlik göstermiş, hem de yüksek içeriklerde seyretmiştir. Yeşil olum döneminde keskin bir düşme göstermiş siyah olum döneminde tekrar artış göstermiştir. Mangan içeriği meyve tutum döneminde en yüksek değerde belirlenmiş bu dönemden siyah olum dönemine kadar stabil seyretmiş ve istatistiki olarak aynı grup içerisinde yer almıştır. Çinko içeriği en düşük çekirdek sertleşmesi döneminde belirlenmiş olup istatistiki olarak pembe olum ve siyah olum dönemlerinde ki içeriklerle aynı grupta yer almıştır. Meyve tutumu ve çekirdek sertleşmesi dönemlerinde en yüksek içeriğe sahip olmuş ve aynı grup içerisinde yer almıştır. Çizelge 6'da görüldüğü gibi makro elementlerden $\mathrm{P}$, mikro elementlerden de $\mathrm{Mn}$ diğer elementlere göre meyvenin gelişme periyodu boyunca diğer elementlere göre daha stabil bir durum göstermektedir.

Çizelge 6. Zeytin danesinin dönemlere göre makro ve mikro element içeriklerinin değişimi Table 6. Variation of macro and microelement contents of olive fruit according to periods

\begin{tabular}{|c|c|c|c|c|c|c|c|c|c|c|}
\hline \multirow{3}{*}{$\begin{array}{l}\text { Dönem } \\
\text { (Period) }\end{array}$} & \multicolumn{10}{|c|}{$\begin{array}{l}\text { Zeytin danesinin dönemlerine göre makro ve mikro besin element içerikleri } \\
\text { (Variation of macro and microelement contents of olive fruit according to periods) }\end{array}$} \\
\hline & \multicolumn{5}{|c|}{$\%$} & \multicolumn{5}{|c|}{$\mathrm{mg} \mathrm{kg}^{-1}$} \\
\hline & $\mathrm{N}$ & $P$ & $\mathrm{~K}$ & $\mathrm{Ca}$ & $\mathrm{Mg}$ & $\mathrm{B}$ & $\mathrm{Cu}$ & $\mathrm{Fe}$ & $\mathrm{Mn}$ & $\mathrm{Zn}$ \\
\hline 1. & $1.00 \mathrm{~b}$ & $0.40 \mathrm{~b}$ & $1.22 \mathrm{~d}$ & $0.59 a$ & $0.27 a$ & $20.06 c$ & $7.65 d$ & $25.90 b c$ & $10.68 a$ & $21.18 a$ \\
\hline 2. & $0.78 c$ & $0.35 b$ & $1.28 \mathrm{c}$ & $0.56 a b$ & $0.24 b$ & $22.07 \mathrm{~b}$ & $6.01 \mathrm{e}$ & $22.29 b c$ & $9.14 a b$ & $11.67 c$ \\
\hline 3. & $1.01 b$ & $0.41 b$ & $1.47 a$ & $0.47 c$ & $0.26 a b$ & $10.26 \mathrm{e}$ & $9.16 c$ & $46.25 a$ & $7.52 \mathrm{ab}$ & $20.45 a$ \\
\hline 4. & $0.82 c$ & $0.39 b$ & $1.30 \mathrm{c}$ & $0.48 c$ & $0.22 c$ & $25.14 a$ & $16.30 \mathrm{~b}$ & $20.08 c$ & $6.06 b$ & $13.98 b$ \\
\hline 5. & $1.25 a$ & $0.54 a$ & $1.42 b$ & $0.50 b c$ & $0.24 b c$ & $15.45 d$ & $20.04 a$ & $13.47 d$ & $6.04 b$ & $12.56 \mathrm{bc}$ \\
\hline 6. & $0.90 b c$ & $0.38 b$ & $1.42 \mathrm{ab}$ & $0.51 b c$ & $0.25 a b$ & $25.35 a$ & $7.25 d$ & $28.19 b$ & $6.15 b$ & $12.82 \mathrm{bc}$ \\
\hline
\end{tabular}

Ayvalık zeytin çeşidi meyvelerinin farklı gelişme periyodu boyunca göre içerdiği bitki besin elementlerin değişimlerinin belirlenmesine ilave olarak hasat döneminde toplanan zeytin meyvelerinde $100 \mathrm{~kg}$ ürün ile kaldırılan besin maddeleri incelendiğinde makro elementlerden en fazla K'un kaldırıldığı bunu N'un takip ettiği Çizelge 7'de görülmektedir. İkincil elementlerden de Ca en fazla kaldırılmaktadır. Dikmelik 1984; Pekcan ve ark. (2004), yaptıkları çalışmada dört farklı yaş grubuna ait zeytin bahçelerinden seçilen 8'er adet ağaç ile yapılan çalışmada $80 \mathrm{~kg}$ ürün ile toprak $\mathrm{N}$, $\mathrm{P}_{2} \mathrm{O}_{5}$, ve $\mathrm{K}_{2} \mathrm{O}$ sırası ile $323 \mathrm{~g}, 109 \mathrm{~g}, 801 \mathrm{~g}$ olarak belirlenmiştir. Sarıfakıoğlu (1995) memecik, zeytin çeşidinde yaptığı çalışmada dane ve budama atıkları ile topraktan kaldırılan N, P ve K miktarlarını belirlemiştir. Farklı yaşlardaki zeytin ağaçlarının 1 kg ürünle ortalama $4.10 \mathrm{~g} \mathrm{~N}, 1.44 \mathrm{~g}_{2} \mathrm{O}_{5}$ ve $9.96 \mathrm{~g}$ $\mathrm{K}_{2} \mathrm{O}$ kaldırıldığını saptamıştır. Elde ettiğimiz bulgular yapılan çalışmalarla uyumludur. Kaldırılan besin maddelerinin miktarları arasında farklılık olmasının nedeni ağaçların çeşit ve yaşlarının farklı olması, sulama, gübreleme, budama ve bitki sağlığı yönünden gerekli uygulamaların yapılıp yapılmadığına bağlı olarak değişiklik göstermektedir. Bu kültürel uygulamalar üzerine iklim de etkili olmaktadır. 
Çizelge 7. 100 kg ürün ile kalkan $\mathrm{N}, \mathrm{P}_{2} \mathrm{O}_{5}$ ve $\mathrm{K}_{2} \mathrm{O}$ miktarları (g) Table 7. The amounts of $\mathrm{N}, \mathrm{P}_{2} \mathrm{O}_{5}$ and $\mathrm{K}_{2} \mathrm{O}(\mathrm{g})$ removed by 100 $k g$ yield

\begin{tabular}{|l|c|c|c|c|c|}
\hline $\begin{array}{l}\text { Ürün (kg) } \\
\text { (Yield) }\end{array}$ & $\mathrm{N}$ & $\mathrm{P}_{2} \mathrm{O}_{5}$ & $\mathrm{~K}_{2} \mathrm{O}$ & $\mathrm{CaO}$ & $\mathrm{MgO}$ \\
\cline { 2 - 6 } & \multicolumn{5}{|c|}{$\mathrm{g}$} \\
\hline 100 & 350 & 120 & 660 & 2040 & 40 \\
\hline
\end{tabular}

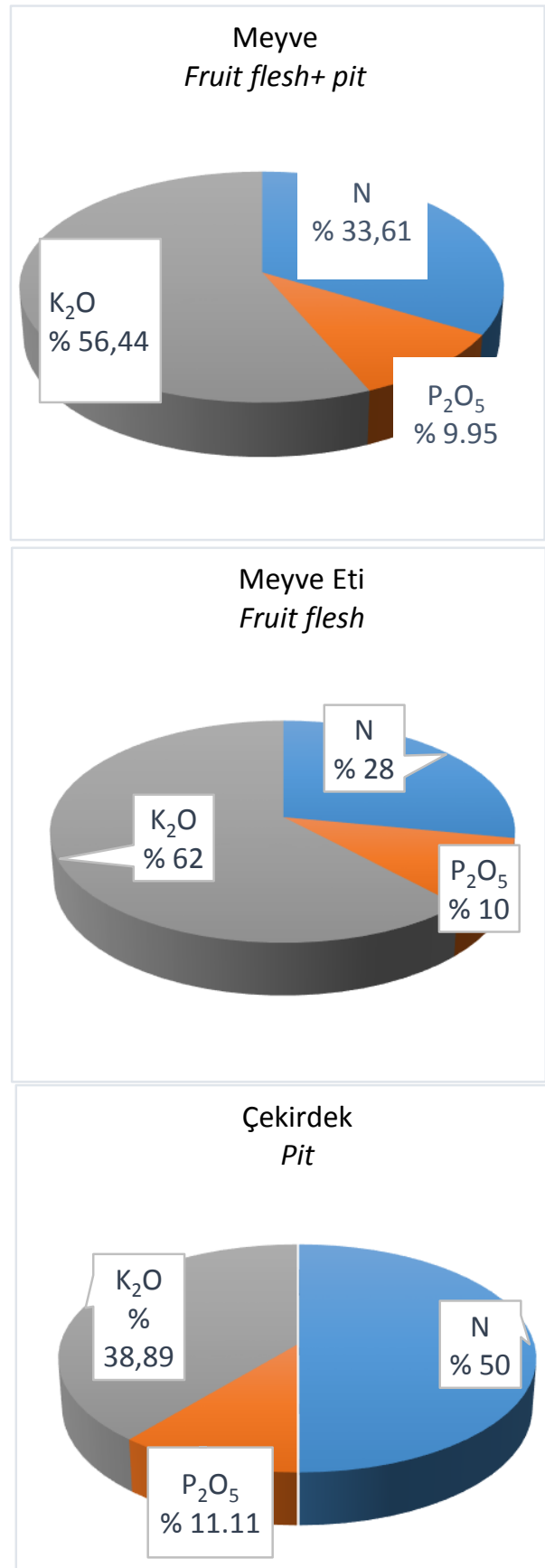

Şekil 3. Meyve ile kalkan \% $\mathrm{N}, \mathrm{P}_{2} \mathrm{O}_{5}$ ve $\mathrm{K}_{2} \mathrm{O}$ Dağılımı Figure 3. Distribution of $\mathrm{N}, \mathrm{P}_{2} \mathrm{O}_{5}$ and $\mathrm{K}_{2} \mathrm{O}$ (\%) removed by fruit

Kaldırılan besin elementlerinin \% dağılımları Şekil 3'de incelendiğinde tüm meyvede \% 56.44 $\mathrm{K}_{2} \mathrm{O}$, daha sonra \% 33.61 ile $\mathrm{N}$ izlerken; ayrı ayrı incelendiğinde meyve eti en fazla $\mathrm{K}_{2} \mathrm{O} \% 62$, çekirdek de ise $\mathrm{N} \% 50$ kaldırılmaktadır. Meyve eti ve çekirdekte bulunan $\% \mathrm{P}_{2} \mathrm{O}_{5}$ miktarının birbirine yakın olduğu gözlenmektedir. Yapılan bir çalışmada dane ile $\mathrm{N} \% 34, \mathrm{P}_{2} \mathrm{O}_{5} \% 15$ ve $\mathrm{K}_{2} \mathrm{O} \% 51$ olarak kaldırıldığı şeklinde ifade edilmiştir (Dikmelik 1984; Pekcan ve ark. 2004). Elde edilen bulgular çalışmamızla uyumludur.

\section{Sonuçlar}

Toprağın fiziksel durumu ve besin elementi içeriğine bağlı olarak, bitkinin beslenmesini en iyi şekilde yapraklardaki besin element miktarı belirlemektedir. $\mathrm{Bu}$ da meyvenin beslenmesi, kalite ve ürün miktarı üzerinde direkt olarak etkili olmaktadır. Yapılan çalışmalarda meyvedeki besin elementlerine ait sınır değerleri bulunmamaktadır.

Sonuç olarak, ürün ile kaldırılan besin elementlerinin miktarları çok yüksektir. Kaliteli ve yüksek verim elde edebilmek için makro ve mikro elementleri, meyvenin ihtiyaç duyduğu dönemden önce uygulamak gerekmektedir. Bu çalışmadan elde edilen bulgular sonucunda; Ayvalık çeşidi zeytin ağaçlarında, meyve tutumundan hasat dönemine kadar geçen gelişme dönemlerinde, zeytin danesinin (çekirdek ve meyve eti) içerdiği bitki besin elementlerinin içerikleri dikkate alındığında, toprak ve yaprak analizlerine dayalı olarak yapılacak olan gübreleme programında zeytin ağaçlarında ilk gübreleme sürgünlerde göz kabarmasından önce yapılması gerektiği söylenebilir. İkinci N'lu gübrelemenin (nisanmayıs) ise sulama yapılmayan bahçelerde son yağışlardan önce (meyve tutum öncesi), sulama yapılan bahçelerde ise ilk sulama ile birlikte toprağa uygulanması gerekmektedir. Fertigasyon programları hazırlanırken; toplam gübre miktarının sulama sayısına bölünmesinin yanında, meyvenin gelişme dönemlerine göre ihtiyaç duyduğu bitki besin elementlerinin meyvenin gelişim dönemine göre doz ayarlaması yapılarak uygulanması sağlanmalıdır. Bu şekilde hazırlanacak olan gübreleme programları ile çevre kirliliğine neden olmayan ve topraklarımızın korunmasını sağlayan bitkisel üretimin yapılmasına katkıda bulunacaktır.

Çıkar Çatışması Beyanı: Makale yazarları aralarında herhangi bir çıkar çatışması olmadığını beyan ederler. 


\section{Kaynaklar}

Deliboran. A. Savran. K, Dursun. Ö, Eralp. Ö, Pekcan. T, Turan. H.S, Aydoğdu. E. Ataol. Ölmez. H, Savran. Ş, Suat. Nacar. A, (2019). Muğla İlinde Yetiştirilen Zeytin (Olea europaea L.) Ağaçlarının Bor ve Mikro Elementler Yönünden Beslenme Durumunun Belirlenmesi, Yaprak ve Toprak Ilişsileri. Uazimer Uluslararası Anadolu Ziraat Mühendisliği Bilimleri Dergisi 2019 (Özel Sayı) 126-14, ISSN:2667-7571.

Dikmelik, Ü. (1984). Farklı Yaşlardaki "Memecik” Zeytin Ağaçlarında Dane ve Budama Artıkları ile Topraktan Kaldırılan Azot, Fosfor ve Potasyum Miktarının Saptanması. Zeytincilik Araştırma Enstitüsü Ülkesel Zeytincilik Araştırma Projesi Sonuç Raporu, Bornova, İzmir.

Doran, İ., ve Aydın, R. (1999). İçel Yöresi Zeytinliklerinin Beslenme Durumunun Tespiti. Anadolu, J. Of AARI. 9(1):105-130.

Eryüce, N., ve Püskülcü, G. (1995). Mineral Nutrition and Some Quality Characteristics of the main olivecultivars of western Turkey. International Symposium on Quality of fruit and Vegetables Influence of Pre-and Post Harvest Foctors and Technology. 20-24 Semptember 1993. Chania, Greece.

FAO. (2019). Food and Agriculture Organization of The United Nations Statistics. Retrieved From: Web: http://www.fao.org/faostat3.fao.org/download/Q/Q C/E Date of Access: 19.02.2020.

http://www.fao.org/land-water/databases-andsoftware/crop-information/olive/en/

Ferreira Llmas, J.F. (1984). Basis of Fertilization in Olive Cultivation and the Olive Tree's vegetative Cycle and Nutritional Needs International Course on the Fertilization and Investive Cultivation of the Olive.

Haspolat, G., ve Nikpeyma, Y., (2009). Gemlik Zeytin Çeşidinde Biyolojik Olarak Şelatize Edilmiş $\mathrm{KNO}_{3} \mathrm{ZnSO}_{4}$ ve $\mathrm{MgSO}_{4}^{\prime}$ ın Yapraktan uygulanmasının ve Plastik Malç Uygulamasının Meyve Verimine ve Kalitesine Etkisi. KSÜ Doğa Bilimleri Dergisi. KSU J. Nat Sci., 12(2). S:1-10.

IOC, (2020). Inter National Olive Council, Survey \& Assesment Division. Retrieved From: Web:http://www.internationaloliveoil.org/estaticos/ view/130-survey-and-asessment-division Date of Access:29.10.2020.

Jordao P.Y., Leitao,F. (1990). The Olive's Mineral Composition and Some Parametres of Quality in Fifty
Olive Cultivars Grown in Portugal. Acta Horticulture, 286. Olive Growing.

Kacar B., ve İnal, A. (2008). Bitki Analizleri, Nobel Yayın No: 1241 Ankara, s: 171-212.

Kacar B. (1972). Bitki ve Toprağın Kimyasal Analizleri, II. Bitki Analizleri, A.Ü. Ziraat Fakültesi Eğitim, Araştırma ve Geliştirme Vakfı Yayınları, No: 3 Bizim Büro Basınevi, Ankara, s: 646.

Mete, N., ve Çetin, Ö. (2017). Zeytinde Genom Haritalama Çalışmaları. Zeytin Bilimi. ISSN: 1309-5889. cilt 7. sayı 1. s: 33-37.

Özilbey, N. (1997). Zeytinde Bazı Bitki Büyüme Düzenleyicilerin ve Yaprak Gübrelerinin Mahsul Miktarı ve Kalitesie Etkileri Üzerine Bir Araştırma. Doktora Tezi, İzmir.

Papastamataki, A.J. (1971). Travail Preliminaire concernent les changements de la Taneur en Composes Mineraux des Olives dele Variate "Concerviola" cito III.II-18.

Pekcan, T., Çolakoğlu, H., Turan, H.S., Yavuz, N., (2004). Ege ve Marmara Bölgesindeki zeytinliklerin toprak özellikleri ve mineral gübrelemenin verim üzerine etkisi. Türkiye 3. Ulusal Gübre Kongresi, Tarım-SanayiÇevre, Bildiriler Kitabı, Cilt: 1, 11-13 Ekim 2004, s: 277 284, Tokat

Sarıfakıoğlu, C. (1995). Bazı Zeytin Çeşitlerinde Yaprak ve Meyvede Mineral Besin Maddelerinin Mevsimsel Değişimi ve Ürün ile Kaldırılan Besin Maddelerinin Belirlenmesi, Ege Üniversitesi Ziraat Fakültesi Bahçe Bitkileri Bölümü, Doktara Tezi, Bornova-İzmir.

Seferoğlu, S. (1996). Ayvalık ve Edremit Yöresinde Yetiştirilen Ayvalık Zeytin Çeşidinin Beslenme Statüsü ile Kimi Ögeleri Arasındaki ilişskiler, E.Ü.Z.F. Toprak Bölümü Doktora Tezi, Bornova-izmir. s:80-88.

TÜiK. (2019). Türkiye İstatistik Kurumu, Bitkisel Üretim İstatistikleri, Web: http://tuik.gov.tr/PrelstatistikTablo.do.istab_id=1073 Erişim: 10.03.2020

Zarcinas, B.,A., Cartwright, B., Spauncer, L.P.1987. Nitric Acid Digestion and Multielement Analysis of Plant Materail by Inductively Coupled Plasma Spectrometry, Commun. Soil Sci. Plant Anal., 18: 131-147.

Zincircioğlu N. (2010). Organik ve Geleneksel Zeytin Yetiştiriciliğinde Bitki Beslenme Durumunun Meyve, Yaprak ve Zeytin Yağında Önemli Kalite Ölçütleri Üzerindeki Etkilerinin Belirlenmesi. Ege Üniversitesi Fen Bilimleri Enstitüsü, Doktora Tezi, Bornova-İzmir, 132s.

Zincircioğlu N. (2018). Domat Zeytin Çeşidinde Meyve-Yaprak Besin Elementleri Değişimlerinin İncelenmesi. Ziraat Fakültesi Dergisi, 55(2). 